\title{
O que o passado tem a nos ensinar sobre a Influenza?
}

\author{
What does the past have to teach us about influenza? \\ ¿Qué puede enseñarnos el pasado sobre la Influenza?
}

Mercedes Neto'; Fernando Porto"

\begin{abstract}
RESUMO
Objetivo: apresentar narrativa dos acontecimentos históricos sobre a epidemia de Influenza e suas interfaces com a saúde pública e enfermagem. Conteúdo: destaca-se a cultura, e os modos de ver a história ao longo dos anos para compreensão do comportamento epidemiológico da Influenza no Brasil, suas epidemias e o que se apreendeu e construiu após 100 anos cuidando e estudando sobre este agravo durante as epidemias que ocorreram no Brasil. Conclusão: entender que a imunização é a estratégia mais eficaz no controle de doenças transmissíveis e, no caso da Influenza, como imunobiológico potente, deve ser o legado apreendido das grandes epidemias deste agravo, mas também, a vigilância e educação em saúde das populações para tal, principalmente com foco nos movimentos antivacinas.
\end{abstract}

Descritores: Influenza; epidemia; enfermagem; saúde pública.

\section{ABSTRACT}

Objective: to present a narrative of historical events regarding the influenza epidemic and its interfaces with public health and nursing. Content: the study highlights culture and ways of seeing history over the years, in order to understand the epidemiological behavior of influenza in Brazil, its epidemics, and what has been learned and built after 100 years' caring for and studying this condition during epidemics that occurred in Brazil. Conclusion: immunization is the most effective strategy for controlling communicable diseases and, in the case of Influenza, is a powerful immunobiological resource. This should be the legacy learned from the major epidemics of this disease, as well as health surveillance and education of the public for the same purpose, with a special focus on anti-vaccine movements.

Descriptors: Influenza; epidemic; nursing; public health.

\section{RESUMEN}

Objetivo: presentar narrativa de los sucesos históricos sobre la epidemia de Influenza y sus interfaces con la salud pública y la enfermería. Contenido: se destacan la cultura y los modos de ver la historia a lo largo de los años, para comprender el comportamiento epidemiológico de la Influenza en Brasil, sus epidemias y lo que se aprendió y construyó después de 100 años cuidando y estudiando sobre este agravio durante las epidemias que ocurrieron en Brasil. Conclusión: entender que la inmunización es la estrategia más eficaz en el control de enfermedades transmisibles y, en el caso de la Influenza, como inmunobiológico potente, ese debe ser el legado comprendido de las grandes epidemias. Asimismo, se debe llevar en cuenta la vigilancia y la educación en salud de las poblaciones, principalmente con foco en los movimientos antivacunas.

Descriptores: Influenza; epidemia; enfermería; salud pública.

\section{INTRODUÇÃO}

Em 2018, completaram-se 100 anos da primeira epidemia da gripe no Brasil. Esta, que é uma doença respiratória infecciosa de origem viral, a qual pode levar ao agravamento e ao óbito, em especial na população-alvo para a infeç̧ão (crianças menores de cinco anos de idade, gestantes, adultos com 60 anos ou mais, portadores de doenças crônicas não transmissíveis e outras condições clínicas especiais).

Por isso, a estratégia de vacinação contra a Influenza foi incorporada no Programa Nacional de Imunizações em 1999, com o propósito de reduzir internações, complicações e mortes na população-alvo para a vacinação no Brasil. Dessa forma, os autores deste ensaio propuseram-se a apresentar aspectos históricos das epidemias e pandemias da gripe, permeando as ações sanitaristas realizadas durante esses 100 anos da gripe no Brasil.

Para tanto, o texto foi estruturado pela síntese da historicidade da doença e, em seguida, pela narrativa das ações sanitaristas hodiernas que tentam combater o movimento antivacinas, o qual propiciou a (re)emergência da gripe como doença de alerta para novas epidemias. Portanto, caracteriza-se como um estudo de reflexão, com o objetivo apresentar narrativa dos acontecimentos históricos sobre a epidemia de Influenza e suas interfaces com a saúde pública e enfermagem.

'Enfermeira. Doutora. Professora Adjunta. Universidade do Estado do Rio de Janeiro. Rio de Janeiro, Brasil. E-mail: mercedesneto.uerj@gmail.com "Enfermeiro. Doutora. Professor Adjunto. Universidade Federal do Estado do Rio de Janeiro. Rio de Janeiro, Brasil. E-mail: ramosporto@openlink.com.br 


\section{A EPIDEMIA DE INFLUENZA}

\section{Precursores da epidemia de Influenza}

Historicamente, sabe-se que foi Hipócrates a fazer referência ao termo Influenza e apresentá-lo. Desse modo, pode parecer redundante a opção pela narrativa da temporalidade e do verossímil no que concerne aos idos de 412 a.C., na Grécia. Na época, foi observado por ele que um determinado agravo à saúde do sistema respiratório acometia diversas pessoas e em poucas semanas as dizimava. Para isso, eram utilizadas sangrias, com base na teoria dos humores, pois se acreditava que a eliminação de sangue excessivo poderia curar as pessoas desta doença ${ }^{1}$.

Desta forma, no entendimento que os indivíduos que foram acometidos não moravam nas cidades - epidemos -, Hipócrates comparou as doenças infecciosas que não eram de determinada região e desapareciam, e deu origem ao termo epidemia. Durante séculos, várias foram as epidemias deste agravo, até que, no século XVIII, três surtos dessa doença em uma determinada região chamaram a atenção e promoveram registros que deram validade ao surgimento do termo Influenza. A ele são atribuídas diversas teorias sobre a origem do nome, desde a influência dos astros até a interferência climática do frio, o que pode ser explicado ao se relacionar as baixas temperaturas acometendo a parte respiratória do ser humano ${ }^{2}$

Os cuidados e tratamentos recomendados eram a castidade, por acreditarem que a patologia estava relacionada ao excesso de relações sexuais, pensamento que perdurou até o século XIX ${ }^{1}$. Até a grande epidemia compreendendo a causa como Influenza, os cuidados e o seu manejo eram pouco desenvolvidos e, muitas vezes, não identificados.

\section{0 anos de epidemia de Influenza}

Até a descoberta da vacina, muitos foram acometidos e dizimados pela Influenza. No período de 1889-1890, temse o registro da Gripe Russa, com sintomas de febre e pneumonia, a qual resultou na perda de 1,5 milhão de vidas, aproximadamente. No período de 1918-1919, houve um surto, no pós-guerra, da chamada Gripe Espanhola. Os doentes apresentavam pneumonia viral, sangramentos e calafrios e vários continentes foram afetados, com uma estimativa de $65 \%$ da população mundial atingida, o que representou em torno de 35.240 óbitos $^{1,3}$, incluindo-se, nessa estatística, o Brasil.

Destaca-se que, nesse período, nas quatro primeiras décadas do século $X X$, os cuidados a esses enfermos eram banhos quentes, ingestão de vinho e canja de galinha, uso da medicação quinino e purgantes. Ressalta-se ainda que, somente em 1945, surgiu a vacina nos Estados Unidos, com apoio do microscópio, a partir de vírus mortos. Sua popularização aconteceu nos anos 1960 e, em 2003, ela foi reconfigurada com o vírus vivo².

A Organização Mundial de Saúde (OMS), em 1947, desenvolveu um sistema de vigilância epidemiológica para a Influenza em diversos continentes; mesmo assim, outros surtos pandêmicos ocorreram ${ }^{3}$. No período de 1957-1958, a Gripe Asiática foi veiculada na imprensa. Seus sinais e sintomas eram febre alta, dor de cabeça e cansaço. Tal gripe atingiu, além da Ásia, a Europa, a África, a Oceania e os Estados Unidos da América, dizimando dois milhões pessoas ${ }^{4}$. Algumas áreas chegaram a parâmetros de $10 \%$ a $20 \%$ da população atingida, havendo maior repercussão em idosos 5 .

A causa da Gripe Asiática foi o vírus A/Singapura/1/57 (H2N2), com a emergência de Hemaglutinina e Neuraminidase de diferentes tipos que circularam ${ }^{6}$. Dez anos depois, era a Gripe de Hong Kong (H3N2) (1968-1969). Os acometidos apresentavam febre alta, dor nas articulações e cansaço no corpo ${ }^{1}$, quando atingiu a população da Ásia, da Oceania, da Europa e dos Estados Unidos da América com 01 milhão de mortes. Esta epidemia apresentou similitudes à de $1957^{7,8}$.

No final do século XX e início do XXI, veio à tona o conhecimento da Gripe Aviária (1997-2004), tendo por sintomas a febre, tosse e dores na garganta, atingindo a população do sudeste asiático, Europa e África. Houve registros de 373 casos, com 236 mortes, dados estes reportados pela $\mathrm{OMS}^{6}$. Mediante ao exposto, pode-se identificar similitudes nos sintomas apresentados, considerando a mutação do vírus, mas com queda vertiginosa no que se refere aos registros de óbito. O desconhecimento a respeito de como a doença se comportava e de como se transmitia, bem como a ausência de busca especializada, a não ser nos casos graves ${ }^{8}$, eram um impeditivo da solução para a Influenza. Com o conhecimento das causas da doença, foram criadas medidas preventivas de contágio e consequente redução das mortes.

Apesar dos avanços, e dos anos que seguiram, o Brasil não conseguiu controlar a Influenza, o que gerou a ocorrência de uma nova pandemia em 2009. Esta foi considerada um marco importante para o aprimoramento da vigilância no país, principalmente nos avanços que esta situação de saúde trouxe como desdobramentos ao conhecimento sobre o vírus e suas mutações, mas também promoveu a compreensão acerca da vacinação como pontochave na eliminação desta doença transmissível ${ }^{9}$. 
Destaca-se que o Programa Mundial de Influenza da OMS, que existe há 70 anos, tem como principais componentes a resposta e a vigilância a essa enfermidade. A iniciativa conta, atualmente, com uma rede de 144 laboratórios nacionais, seis centros colaboradores, quatro laboratórios reguladores essenciais, 13 laboratórios de referência, um centro colaborador para vigilância epidemiológica e outro para estudos ecológicos ${ }^{9}$.

Em 2018, completaram-se 100 anos da maior crise de saúde pública da história moderna - a Gripe Espanhola -, que infectou cerca de um terço da população mundial em 1918. Um século depois, o conhecimento e as tecnologias para lidar com tais pandemias são sofisticados e podem ajudar não só os países a responderem a elas, mas também a diminuírem seus efeitos devastadores, como altas taxas de mortalidade e incapacidades à população.

\section{A vigilância em saúde e a imunização no controle da Influenza}

Cem anos se passaram no Brasil desde a epidemia da Gripe Espanhola e, em alguns espaços, parecem esquecer que a cada temporalidade novos vírus da gripe circulam pelo mundo, com necessidade de se estabelecer estratégias de barreiras vivas. Isto posto, a Organização Mundial da Saúde determina, anualmente, quais são os vírus de maior circulação para a fabricação da vacina contra Influenza, com recomendação aos governos perante vigilância e ampliação dos programas nacionais de vacinação ${ }^{9}$. A vigilância da Influenza no Brasil é composta pela vigilância-sentinela de Síndrome Gripal (SG), de Síndrome Respiratória Aguda Grave (SRAG) em pacientes internados em Unidade de Terapia Intensiva e pela vigilância universal de SRAG. Esta vigilância monitora os casos hospitalizados e óbitos com o objetivo de identificar o comportamento da Influenza no país para orientar na tomada de decisão do Ministério da Saúde e Secretarias de Saúde Estaduais e Municipais ${ }^{10}$

Além disso, promove campanhas anuais de imunização contra este agravo, o que compete ao governo brasileiro, como obrigatoriedade, o acesso à vacina contra a doença de forma a ser público, e sua distribuição ocorre sem custos para os usuários do Sistema Único de Saúde (SUS). No país, houve uma importante redução nos níveis de endemia, como resultado de estratégias nacionais de controle, sobretudo a vacinação de grupos vulneráveis, tais como profissionais de saúde, crianças, gestantes, puérperas, idosos ${ }^{11}$.

A cultura da imunização no Brasil, expressa na adesão da população aos programas e na demanda por novas vacinas a serem oferecidas pelo setor público, remonta ao processo de introdução de vacinas no século XIX e às campanhas de vacinação em massa empreendidas pelo Estado brasileiro ${ }^{3}$. No país, referência para muitos outros na área de Imunização, a vacinação ocupa lugar de destaque entre as ações de Saúde Pública ${ }^{10}$.

As políticas de imunização tornam-se cada vez mais complexas em suas dimensões global e nacional. Para que as metas de Saúde Pública sejam alcançadas, é necessária a aceitação à imunização pela população. Entretanto, a informação disponível, seja de livros, notícias de televisão, artigos de jornal ou fontes on-line tem um grande impacto na forma como o público percebe as vacinas. Isto se deu pelo impacto da publicação de Andrew Wakefield na revista médica The Lancet, em 1998, na qual o referido autor apoiava uma relação entre a vacina contra a caxumba, o sarampo e a rubéola (MMR) e o autismo. Esta mensagem tornou-se comum e continua a ser uma preocupação significativa entre os pais, mesmo após a revista ter se retratado, apenas em 2010, pela publicação do artigo e por deslustrar a descoberta ${ }^{12}$.

O fato de a notícia sobre uma possível relação entre o autismo e a MMR advir a partir de artigos científicos publicados em revistas respeitáveis e autoritárias levou não somete à população a temer pela imunização, mas a preocupação generalizada entre os profissionais de saúde. Isso parece ser verdade hoje, quando os artigos publicados em revistas acadêmicas de variada respeitabilidade podem ter um impacto significativo, pois podem ser vistos como uma base científica para posições antivacinas e céticas ${ }^{12}$.

Nestas notícias é possível identificar o resquício da Revolta da Vacina, nos discursos e na falta de compreensão científica dos benefícios das vacinas. A disseminação de informações e inclusive pesquisas que corroboram para não vacinação, promovem contágios de doenças que deveriam estar erradicadas, como por exemplo, sarampo e poliomielite ${ }^{13}$.

Os estudos observacionais mostraram uma associação entre a exposição à informação antivacinas no twitter e na internet em geral, e uma percepção negativa dos riscos das vacinas. Um segundo estudo, canadense, com 250 mães, também relatou que a dependência de sites governamentais, que promovem a vacinação, está associada a taxas mais altas de vacinação. Assim, fica difícil estabelecer uma associação e quantificar o impacto das informações on-line sobre a aceitação de vacinas ${ }^{9}$.

Destaca-se que, para as áreas de atuação da enfermagem, principalmente aos profissionais da Atenção Primária à Saúde que trabalham na sala de vacinas, nos serviços de vigilância, e nos cuidados com as populações nos territórios, o discurso do movimento antivacinas promove pouca aceitação das vacinas e dúvidas quanto a sua eficácia e real necessidade. 
Não se pode confirmar que os imunobiológicos estão totalmente livres de riscos, mas exige dos profissionais de saúde o desenvolvimento de esclarecimentos nas atividades vacinais para que a incidência das doenças imunopreveníveis não se configure como há tempos atrás ${ }^{14}$. Ademais, nos últimos anos, a população-alvo para a imunização contra a gripe tem atingido a meta lançada pelo Ministério da Saúde da cobertura vacinal, que seria de $90 \%$.

Contrariamente, o grupo de gestantes e crianças, que são as de seis meses a menores de cinco anos, além dos estados de Roraima, Rio de Janeiro e Acre, mantêm-se abaixo da cobertura esperada. Isto pode ter relação com a não adesão à vacina da população, sendo este agravo possível, principalmente, no que tange à ausência de adesão à vacinação e aos cuidados com a vigilância epidemiológica dos casos novos, mas, principalmente, dos sorotipos circulantes ${ }^{15}$.

Em outras palavras, a vigilância em saúde da Influenza, bem como a construção de estratégicas para sua eliminação, vão além das tecnologias de tratamento e prevenção. A direção destas ações está na educação em saúde das populações, compreendendo a imunização como estratégia ímpar para controle e eliminação da Influenza no território brasileiro.

\section{CONCLUSÃO}

A erupção da epidemia de Gripe Espanhola evidenciou o caráter incipiente das ações empreendidas e incapazes de resolver a questão do saneamento urbano e de aparelhar o estado para oferecer à população políticas públicas de saúde amplas, compulsórias, permanentes e eficazes. Em 1918, a população de Salvador ainda estava submetida às precárias condições de saneamento, à carência de serviços de água, esgoto, transporte e às altas taxas de mortalidade provocadas por males endêmicos e epidêmicos. Nessa perspectiva, a Gripe Espanhola foi uma grande epidemia no país que, com grandes repercussões em desfechos letais, trouxe significado e significação dentro de um contexto humano, nos diversos modos pelos quais se infiltra nas vidas das pessoas, nas reações que provoca, e na maneira pela qual dá expressão a valores sociais, culturais e políticos.

No que tange à prevenção da Influenza grave e de suas complicações, a medida mais efetiva é a vacinação contra a doença nos dias atuais. Ressalta-se a necessidade anual de vacinação, pois a vacina é produzida conforme as cepas circulantes no território no ano anterior. Vale destacar que a vacinação, seja para Influenza ou outro agravo, se constitui, ao longo dos anos, uma ação de prevenção efetiva com quebra da cadeia epidemiológica de diversas doenças, que, estrategicamente, se torna uma política pública em saúde reconhecida mundialmente.

Ademais, para o campo da enfermagem, compreender a dinâmica durante este século das diversas epidemias de Influenza que o país enfrentou, é entender o comportamento deste agravo nas populações, logo, possibilita o desenvolvimento profissional nos espaços de atuação, da atenção primária à hospitalar.

\section{REFERÊNCIAS}

1. Black M, Armstrong P. An introduction to avian and pandemic influenza. NSW Public Health Bull [Internet]. 2006 [cited 2019 Jan 15]; 17(7-8): 99-103. DOI: https://doi.org/10.1071/NB06024

2. Oppermann A. Gripes históricas: a história das gripes. Textos Especiais. Revista Aventuras na História. 2009 [cited 2019 Jan 15 ]; 71(1): 1-2; jun./set. Avaiable from: https://historiablog.org/2009/09/04/gripes-historicas-a-historia-das-gripes/

3. Cheng KF, Leung PV. What happened in China during the 1918 influenza pandemic? Int J Infect Dis. [Internet]. 2007 [cited 2019 Jan 16]; 11(4): 360-4. Avaiable from: https://www.ijidonline.com/article/S1201-9712(07)00035-5/fulltext

4. Patterson KD, Pyle GF. The Geography and mortality of the 1918 influenza Pandemic. Bull Hist Med 1991 [cited 2019 Jan 16]; 65(1): 4-21. Avaiable from: https://www.ncbi.nlm.nih.gov/pubmed/2021692

5. Ministério da Saúde (Br). Secretaria de Vigilância em Saúde. influenza, histórico da doença [Online]. Brasília (DF): Ministério da Saúde; 2017. [cited 2019 Jan 18]. Avaiable from: http://portal.saude.gov.br/portal/saude/visualizar_texto.cfm?idtxt=21725

6. Forleo-Neto E, Halker E, Santos VJ, Paiva TM, Toniolo-Neto J. influenza. Rev Soc Bras Med Trop. 2003. [cited 2019 Jan 16]. 36(2): 267-74. Avaiable from: http://www.scielo.br/scielo.php?script=sci_arttext\&pid=S0037-86822003000200011\&lng=pt\&tlng=pt

7. Kawaoka Y, Krauss S, Webster RG. Avian-to-human transmission of the PB1 gene of influenza a viruses in the 1957 and 1968 pandemics. [Internet]. Journal of Virology. 1989 [cited 2019 Jan 18]; 63 (11): 4603-8. Avaiable from: https://www.ncbi.nlm.nih.gov/pubmed/2795713

8. Ribeiro AF. Influenza - Trajetória no Século XX. Boletim Epidemiológico Paulista. 2007 [cited 2019 Jan 15]; 4(41):15-17. Avaiable from: http://periodicos.ses.sp.bvs.br/pdf/bepa/v4n41/v4n41a03.pdf

9. Organização Pan-Americana de Saúde. Banco de Notícias. Preparação e resposta a pandemias de Influenza são tema do último dia do MedTrop 2018. Brasil, 2018 [cited 2018 Oct 10]; Avaiable from: https://www.paho.org/bra/index.php?option=com_content\&view=article\&id=5754:preparacao-e-resposta-a-pandemias-deInfluenza-sao-tema-do-ultimo-dia-do-medtrop-2018\&Itemid=812

10. Ministério da Saúde (Br). Secretaria de Vigilância em Saúde. Influenza: Monitoramento até a Semana Epidemiológica 42 de 2018. Informe Epidemiológico. Brasil, 2018 [cited 2018 Dec 04]; Avaiable from: https://portalarquivos2.saude.gov.br/images/pdf/2018/outubro/26/Informe-Epidemiol--gico-Influenza-2018-SE-42.pdf 
11. Aguiar MF, Lima CA, Carneiro JA, Martins AMEBL, Santos JAD, Costa, FM. Hepatitis B vaccination and associated factors among nursing personnel at a university hospital. [Internet]. Rev. enferm. UERJ. 2017 [cited 2019 Jan 12]; 25:e18856. DOI: https://doi.org/10.12957/reuerj.2017.18856

12. Neto M, Rodrigues FS, Lima DCJ, Abrêu, MJO, Espirito Santo, TB, Rafael, RMR. La Revuelta de la Vacuna: la lectura iconográfica de la portada de la Revista da Semana (1904). [Internet] Rev. Cult de los Cuidad. 2018 [cited 2019 aug 19] 22(52):75. Avaiable from: http://dx.doi.org/10.14198/cuid.2018.52.06

13. Arif N, Al-Jefri M, Bizzi IH, Perano GB, Goldman M, Haq I et al. Fake News or Weak Science? Visibility and Characterization of Antivaccine Webpages Returned by Google in Different Languages and Countries. Front Immunol. 2018 [cited 2018 Dec 12]; 9:1215. Avaiable from: https://www.frontiersin.org/articles/10.3389/fimmu.2018.01215/full

14. Costa NMN, Leão AMM. Reported cases of adverse events following immunization: contribution to nursing care. Rev. enferm. UERJ. 2015 [cited 2018 Dec 12]; 23(3):297-303. DOI: http://dx.doi.org/10.12957/reuerj.2015.14850

15. Ministério da Saúde (Br). Vacina contra gripe atinge $90 \%$ do grupo prioritário. Brasília (DF): Ministério da Saúde; 2018. [cited 2018 Dec 04] Avaiable from: http://portalms.saude.gov.br/noticias/agencia-saude/43866-meta-de-vacinacao-contra-gripe-eatingida-no-pais 